\title{
A Contabilidade sob o enfoque sociológico: uma abordagem das teorias semióticas e da comunicação
}

\section{Resumo}

O trabalho procura demonstrar que a informação contábil, apoiada em conceitos da semiótica e da teoria da comunicação, pode desempenhar papel de grande importância na construção e manutenção da ordem social. Parte-se do pressuposto de que a finalidade básica da Contabilidade não se resume ao fornecimento de informações destinadas a otimizar decisões de caráter econômico, mas que essa disciplina deve contribuir também para promover o diálogo entre a empresa e os diversos agentes que com ela se relacionam, estimulando, assim, o exercício da cidadania.

Destaca-se que, sob o enfoque sociológico, a Contabilidade é chamada a por ordem onde reina o caos, procurando desenvolver e consolidar uma cultura empresarial que privilegie a transparência e permita à sociedade conhecer e avaliar ações que ajudem a conciliar sucesso econômico com os ideais de justiça. Nestes termos, entende-se que não seria exagero afirmar que a ordem social depende, pelo menos em parte, da ordem contábil.

Finalmente, entende-se que as teorias semióticas e da comunicação podem contribuir para melhorar as funções da Contabilidade como instrumento de apoio à ordem social, uma vez que elas fornecem metodologias úteis para avaliar a eficácia do ato comunicativo e facilitam a apresentação de informações significativas para os diversos públicos que se envolvem com a empresa.

\section{Abstract}

This text reaches to demonstrate that the accounting information, based on the semiotics and communication theory concepts, can to perform the role of large importance in the social order construction and maintenance. It takes as presuppositions as the basic finality of the Accountability doesn't resume in supplying information destined to overcome economic character decisions, but that that discipline must also contributing to promote the dialogue between the company and the diverse agents whose are related to it in stimulating the citizenship exercise.

It emphasizes that under the sociological focus, the Accountability is called to put order where the chaos exists, looking for developing and consolidating a enterprise' culture which privileges the transparence and permits to society know edging and evaluating actions that to help conciliating economic success with the justice ideals.

In these terms, certainly, it is possible to affirm that the social order depends on accounting order or, by means, in part.

Finally, it understands that the semiotics and the communication theory can to contribute for ameliorating the Accountability functions as a support instrument for the social order, indeed they furmish useful methodologies for evaluating the communicative act efficacy and aiding the presentation of significant information to the different public whose are involved with the company.

\section{Introdução}

O presente trabalho tem por objetivo estimular reflexões sobre possíveis contribuições que as teorias semióticas e da comunicação têm a oferecer à Contabilidade, para que ela possa atuar de forma mais ampla como instrumento de apoio à construção e manutenção da ordem social. Parte-se do entendimento de que a ordem contá-

\footnotetext{
* Professor Titular da Universidade de São Paulo - USP.

** Doutorando em Controladoria e Contabilidade - FEA/USP.
} 
bil, ao lado da jurídica e econômica, também pode contribuir para promover e manter o equilíbrio da sociedade até porque o direito à informação é um dos pressupostos básicos da cidadania.

Que a informação é ingrediente de fundamental importância em qualquer processo decisório parece ser fato amplamente aceito. Sob o aspecto econômico, por exemplo, entende-se que ela deve contribuir para permitir a melhor alocação de recursos visando à otimização de resultados. Nesse sentido, seu objetivo é agregar valor às decisões de forma a diminuir a distância entre os resultados planejados e os realizados.

No caso das informações contábeis, em particular, considera-se que seu principal objetivo é facilitar decisões de investimentos, créditos e outras semelhantes. Sob esse prisma, os agentes que recorrem a informações dessa natureza o fazem esperando encontrar nelas sinais que lhes permitam avaliar riscos, prever fluxos de caixa, elaborar e ajustar planos etc. Esse tem sido o entendimento predominante quanto aos objetivos básicos da Contabilidade.

Apesar disso, pode-se considerar que essa disciplina não deve contribuir apenas para a maximização da riqueza, mas também para satisfazer interesses sociais mais amplos, pelo menos sob a ótica do conceito de accountability. Aqui é necessário destacar que, modernamente, o conceito de accountability não se confunde com a simples prestação de contas que os administradores devem efetuar em relação aos recursos que foram colocados à sua disposição pelos acionistas. Pelo contrário, é algo bem mais amplo e envolve todos os agentes que, direta ou indiretamente, contribuam para o sucesso das organizações. Nesse conjunto, com certeza, pode-se incluir empregados, clientes, fornecedores, sindicatos, entidades ambientalistas e a própria comunidade em geral.

Tudo isso nos leva a questionar que tipo de informação contábil deve ser fornecida em uma sociedade que precisa resgatar valores éticos e morais, a quem deve ser fornecida e sob quais conceitos de evidenciação, que tipo de linguagem deve ser adotada para permitir melhor diálogo entre as organizações e os diversos agentes que com ela se relacionam etc. Essa preocupação torna-se mais incisiva, quando se considera que a Lei de Responsabilidade Fiscal atribui à Contabilidade o papel de tornar visível ao cidadão as contas dos gestores públicos. Isso se dá por meio da publicação de demonstrativos que revelem ao contribuinte a utilização dos recursos que ele coloca à disposição dos governantes.

\section{Inter-relações entre Contabilidade, Semiótica e Teoria da Comunicação}

A interface entre Contabilidade, Semiótica e Teoria da Comunicação deriva do fato de que essa primeira disciplina se caracteriza como um processo de identificação, mensuração e comunicação de informações. Além disso, assenta-se na idéia de que ela é um tipo de linguagem que serve para unir o mundo da empresa a diversos elementos, tais como clientes, fornecedores, acionistas, governo, sindicatos, entidades ambientalistas etc. Em tese, todos desejam obter informações que lhes permitam conhecer a empresa, avaliar sua atuação e com ela interagir de forma eficaz.

Como a Semiótica se ocupa do estudo de todos os tipos de linguagem e a Teoria da Comunicação define parâmetros para se avaliar o ato comunicativo, sugere-se que tais disciplinas podem contribuir para aumentar a eficácia da evidenciação contábil.

Para facilitar a assimilação desse raciocínio, apresenta-se a seguir uma rápida visão da Contabilidade como linguagem e também como processo de comunicação. Na seqüência, formula-se uma resumida caracterização da Semiótica, destacando-se alguns conceitos fundamentais.

\subsection{A Contabilidade como linguagem de negócios}

A percepção da Contabilidade como linguagem resulta do entendimento de que a comunicação é função básica dessa disciplina, haja vista que, se as informações contábeis não atin- 
girem seus destinatários tempestivamente e sob forma compreensível, de maneira alguma poderão surtir o efeito desejado.

O uso de palavras e técnicas específicas na composição das mensagens contábeis é outro motivo em que se fundamenta a idéia de que a Contabilidade é uma espécie de linguagem. Esta pelo menos tem sido a avaliação de autores que, como Ijiri (1975:14), afirmam textualmente que a Contabilidade tem muita coisa em comum com outros tipos de linguagem, principalmente no que se refere a regras sintáticas, semânticas e pragmáticas. Nessa mesma linha de raciocínio, encontram-se Chambers (1966), Belkaoui (1995), Horngren (1974) e Anthony (1975), entre outros.

Explorando esse enfoque, Hendriksen (1999:29) confirma que uma das possíveis classificações da teoria contábil se apoia no entendimento de que a Contabilidade é uma linguagem, considerada por muitos como linguagem de negócios. Esse autor acrescenta que, sob esse prisma, pode-se efetuar os seguintes questionamentos sobre as palavras e frases que compõem a linguagem contábil:

1. Que efeito as palavras utilizadas pela Contabilidade terão sobre os usuários das informações contábeis?

2. Que significado tais palavras terão para eles, se houver algum?

3. As palavras se conectam em sentido lógico?

Esse autor esclarece que a resposta a cada uma dessas perguntas faz parte do estudo de uma linguagem. A primeira questão se relaciona com a pragmática, que estuda o efeito da linguagem sobre os indivíduos; a segunda, com a semântica, que estuda o significado das palavras; e a terceira se relaciona com a sintaxe, que estuda as conexões lógicas entre as palavras e frases.

Como linguagem de negócios, o papel da Contabilidade é facilitar a percepção das características relevantes de certos eventos econômicos, levando aos usuários das informações contábeis conhecimentos necessários à otimização de suas decisões. Idealmente, por meio dessa linguagem, os usuários devem ser motivados a adotar as mesmas decisões que adotariam caso estivessem observando os referidos eventos diretamente.

Essa desejada reação depende, entre outros fatores, do grau de acurácia com que os símbolos alfanuméricos utilizados na evidenciação contábil consigam representar os eventos econômicos. Nas palavras do Financial Accounting Standards Board - FASB (SFAC 2), isso depende da fidelidade de representação, que é definida por esse Conselho como a correspondência ou concordância entre uma medida ou descrição e o fenômeno que ela busca representar.

\subsection{A Contabilidade como processo de comunicação}

Há muito tempo, o conceito de Contabilidade como processo de comunicação tem despertado o interesse de diversos autores. Chambers (1966), por exemplo, visualiza a Contabilidade como um processo de comunicação que, como qualquer outro do gênero, deve observar regras sintáticas, semânticas e pragmáticas. De forma semelhante, Littleton e Zimmerman (1962) destacam que a Contabilidade tem no processo de comunicação um meio fundamental ao cumprimento de seus objetivos.

Na mesma linha de raciocínio, Most (1982) considera que a Contabilidade é um processo de comunicação no qual os contadores têm o papel de observar eventos econômicos, mensurar seus atributos e comunicá-los a diversos estratos de usuários por meio de relatórios contábeis. Esse autor sugere que os princípios da Teoria da Comunicação fornecem subsídios relevantes para identificar e corrigir problemas que prejudicam a comunicação contábil.

Iudícibus (1997:26) faz referência à Contabilidade como processo de comunicação, utilizando os seguintes termos: "Este processo de comunicação implica o reconhecimento dos tipos de informação necessária para cada principal usuário da informação contábil e a avaliação da habilidade dos usuários em interpretar a informação adequadamente." Na mesma obra, o referido autor considera que esse enfoque parece ser uma base profícua para a Contabilidade, haja vista que essa disciplina real- 
mente "pode ser conceituada como um método de identificar, mensurar e comunicar informação econômica, financeira, física e social, a fim de permitir decisões e julgamentos adequados por parte dos usuários da informação".

Em regra, os autores que assim se manifestam consideram que a Teoria da Comunicação fornece metodologia para aprimorar a evidenciação contábil, tendo em vista as semelhanças existentes entre o processo geral de comunicação e o processo contábil. Sinteticamente, a referida teoria estabelece que o modelo de comunicação é constituído dos seguintes elementos: fonte, emissor, mensagem, canal e receptor. A fonte produz as mensagens a serem comunicadas. A mensagem é o instrumento que une o receptor ao emissor por meio de um sistema de códigos. O canal é o veículo utilizado para transportar as mensagens. O receptor é o elemento a quem se destina a mensagem.

De acordo com Bierman e Drebin (1979), os componentes do modelo geral de comunicação podem ser visualizados da seguinte forma num sistema contábil: os eventos econômicos constituem a fonte básica da informação, o contador atua como transmissor, após observar tais eventos e codificá-los para formar os relatórios contábeis, os quais, por sua vez, representam o canal desse tipo de comunicação.

Essa abordagem ajuda-nos a compreender que a evidenciação contábil deve ser considerada de forma sistêmica, desde o emissor, a quem cabe identificar, interpretar e codificar os eventos econômicos, até o usuário das mensagens contábeis. Quando se trata de avaliar a eficácia do ato comunicativo, torna-se necessário considerar todos os fatores que, em cada componente do processo de comunicação, concorrem para aumentar ou reduzir a fidelidade da comunicação.

Porém, nesse processo, o usuário da informação sempre será o parâmetro de maior importância. Suas características e necessidades devem ser consideradas com muita atenção, quando se trata de definir o conteúdo das mensagens, o código utilizado em sua composição, o tipo de canal etc. Afinal de contas, é a ele que se dirigem os relatórios contábeis. Em última instância, o usuário é a própria razão da Contabilidade. Daí, a afirmação de que ela é uma disciplina essencialmente utilitária. De fato, por mais esmerada que seja a informação, ela não terá qualquer serventia se não for capaz de contribuir para melhorar as decisões de seus destinatários.

\subsection{A interação entre Semiótica e Contabilidade}

Assumindo a Contabilidade como um processo de identificação, mensuração e comunicação e que o mesmo se desenvolve com o apoio de uma linguagem específica, pode-se aproveitar conceitos da Semiótica para melhorar a qualidade da informação contábil. Isso é o que sugerem diversos autores como Chambers (1966), Mason e Swanson (1981), Etheridge (1991) e Nakagawa (2000).

Para melhor entendimento de como se manifesta a relação entre Contabilidade e Semiótica, é preciso observar alguns passos fundamentais. $\mathrm{O}$ primeiro deles consiste em entender que a Semiótica é uma ciência que se dedica ao estudo de todas as linguagens, contribuindo para avaliar suas funções sintática, semântica e pragmática. De acordo com Morris (1976), a Semiótica funciona como instrumento de todas as ciências, uma vez que fornece uma linguagem geral aplicável a qualquer processo de descrição das propriedades de eventos e objetos. Como a mensuração contábil, em si mesma, nada mais é do que um processo de atribuição de números e palavras a certas propriedades de objetos e eventos econômicos, tem-se aí um ponto de interseção entre as duas disciplinas.

O segundo aspecto em que a Semiótica pode contribuir para aprimorar a evidenciação contábil diz respeito à descrição do processo pelo qual as pessoas percebem as características dos eventos e objetos que tocam a sua consciência. Com a Semiótica, aprende-se que os significados não são propriedades das palavras utilizadas para representar os fenômenos que nos cercam, mas elementos que residem em nossa consciência e 
que nela se instalam em função de determinados referenciais cognitivos do contexto onde atuamos etc. Por isso, pessoas diferentes podem ter percepções bem distintas de um mesmo objeto ou evento.

A Semiótica ajuda-nos a compreender que a percepção das características relevantes dos eventos econômicos e sua subseqüente representação por meio de números e palavras é influenciada pelas habilidades cognitivas de cada indivíduo, pelas características do contexto, pelos níveis de experiência etc. Esse é um fato que precisa ser devidamente considerado, sobretudo na fase de coleta dos dados que alimentam os sistemas contábeis. A qualidade da informação pode ficar seriamente comprometida, quando os indivíduos encarregados da identificação e interpretação dos eventos econômicos não conseguem perceber suas características relevantes.

No campo da análise de balanços, este é um aspecto que tem sido destacado por vários autores. Para citar um exemplo, Schrickel (1999) nos lembra que o uso adequado das informações contábeis não se dá pela simples extração de índices e quocientes dos relatórios, mas sim pela correta compreensão do significado dos números e palavras utilizados na representação dos eventos econômicos.

Discutindo esse problema no contexto das teorias semióticas, Santaella (1998:66) afirma que nossa vida, em qualquer instante, por mais corriqueiro que seja, está repleta de exemplos de situações em que nossa percepção falha. Julgamos ter visto uma coisa, mas, logo depois, verificamos que incorremos em erro, ou seja, constatamos que não era o que pensávamos ter visto. Essa autora explica que os julgamentos de percepção são inferências lógicas, elementos generalizantes que dependem de esquemas interpretativos variáveis. Baseando-se em estudos empreendidos por Peirce, o pai da moderna Semiótica, Santaella explica que todo pensamento lógico e toda a cognição são adquiridos por meio da percepção.

No âmbito da Contabilidade, os produtores das informações contábeis focalizam determinados eventos econômicos, abstraem certas carac- terísticas a eles associadas e procuram representá-las por meio de símbolos alfanuméricos. A correta percepção dos eventos e de suas características relevantes depende também da interpretação de conceitos e normas contábeis. Sobre o problema da percepção, Beladouni (1966:215-25) assim se manifesta:

"Perception of accounting events obviously calls for the identification of their discriminable features. In our attempt to identify the discriminable features of an event, we need not and do not try to obtain an exhaustive description of that event. As in the perception of all events, we select only certain features that are critical for the cognitive act."

A Semiótica pode contribuir ainda para reforçar o entendimento de que a interpretação dos eventos retratados nos relatórios contábeis depende do grau de acurácia com que os códigos utilizados na evidenciação contábil consigam despertar no receptor os significados pretendidos pelo emissor. A teoria dos signos, com sua lógica rigorosa, nos permite entender por que algo significa o que significa.

\section{O papel da ordem contábil na busca da ordem social}

A proposta de utilizar conceitos da Semiótica e da Teoria da Comunicação para aumentar o poder de evidenciação das demonstrações contábeis encontra no enfoque sociológico da teoria contábil uma de suas principais justificativas. A razão é que sob essa abordagem a Contabilidade não deve contemplar apenas os interesses dos acionistas, mas também de outros agentes que se relacionam com a empresa e que podem exercer influência sobre o seu desenvolvimento.

Esse fato nos leva a considerar, por exemplo, se a linguagem empregada na evidenciação contábil está articulada sob um conjunto de signos que possam ser compartilhados por clientes, empregados, associações de proteção ao meio ambiente, sindicatos, instituições de pesquisa etc. Afinal, potencialmente, todos esses agentes po- 
dem precisar de informações contábeis para avaliar a atuação das organizações sob o ponto de vista social. De igual forma, pode-se considerar também a necessidade de outros recursos mais adequados à comunicação das informações contábeis.

Hendriksen (1999:26) adverte-nos de que a visão microeconômica da Contabilidade não abrange, necessariamente, todos os efeitos que as empresas exercem na sociedade. Em sua avaliação, fica uma lacuna a ser preenchida com informações relativas a custos da poluição ambiental, do desemprego, de condições insalubres de trabalho, entre outros fatores de interesse social. Destaca-se que, nesse sentido, a Contabilidade tradicional, com sua ênfase nos acionistas, pode ser considerada um subconjunto da Contabilidade social, que busca alcançar interesses de um leque mais amplo de indivíduos.

Segundo Iudícibus (1997:25), sob a abordagem sociológica, a contabilidade é julgada pelos efeitos que os procedimentos contábeis e os relatórios dela emanados exercem sobre a sociedade. Trata-se, pois, de verificar se tais relatórios atendem a finalidades sociais mais amplas, fornecendo informações que permitam, por exemplo, julgamentos acerca do desempenho das empresas e de suas relações com a sociedade. Parte-se do entendimento de que o acionista não é o único destinatário dos resultados das empresas e que a própria continuidade dos negócios não depende apenas dessa categoria de usuários das informações contábeis.

Seguindo o mesmo raciocínio, Belkaoui (2000) afirma que, sob a referida abordagem, espera-se que os dados contábeis possam contribuir para a promoção do bem-estar social. Esse autor destaca que tal expectativa presume a existência de valores sociais estabelecidos que sejam utilizados como critério na determinação da teoria contábil. Nesse sentido, a sociedade como um todo poderia ser vista como usuário da informação contábil. Kam (1990) manifesta idêntico entendimento, alegando que cada componente da sociedade, de uma forma ou de outra, é afetado por informações dessa natureza. Por isso, esse autor defende a idéia de que pelo menos as empresas de maior porte deveriam publicar informações de cunho social, já que suas ações tendem a provocar maior impacto sobre a vida dos indivíduos.

\subsection{A responsabilidade social das empresas}

Com o fortalecimento das democracias, aliado às novas tecnologias da informação, é provável que, de fato, a sociedade passe a exercer uma maior pressão sobre as organizações, a fim de que elas ampliem evidenciações de interesse social, divulgando dados tais como volume de demissões, contratações, contribuições tributárias, investimentos em programas de preservação do meio ambiente, nível de satisfação dos clientes, insalubridade, segurança no trabalho etc.

Nesse sentido, a evidenciação contábil deve contribuir para desenvolver e consolidar uma cultura empresarial que privilegie a transparência e permita à sociedade conhecer e valorizar esforços tendentes a conciliar sucesso econômico com impactos sociais e ambientais. Para tanto, a Contabilidade deverá usar recursos de evidenciação que facilitem o diálogo da empresa com diferentes públicos envolvidos com suas atividades.

Algumas manifestações dessa natureza já se encontram em curso, a exemplo da proposta de $B a$ lanço Social articulada pelo sociólogo Herbert de Souza (1935-1997). Tais iniciativas partem do princípio de que o progresso tecnológico e o lucro não asseguram a construção de uma sociedade justa e sustentável a longo prazo. De igual forma, baseia-se na premissa de que as condições físicas do planeta não suportam o enorme impacto de um crescimento econômico desordenado. Isso significa que a lógica do lucro deve encontrar na função social da propriedade uma linha delimitadora.

Naturalmente, tudo isso deve exercer reflexos sobre conceitos e diretrizes que norteiam a produção das informações contábeis. Porém, como conhecimento de natureza social, cabe à Contabilidade procurar se ajustar para atender às novas demandas que deverão surgir. A propósito, Hendriksen (1999:165) salienta que a política contábil de um país não pode ficar atrelada a interesses de grupos específicos, tais como investi- 
dores individuais, administradores e contadores. Esse autor acrescenta que, por maior que seja a dificuldade de se admitir esse fato, a política contábil nacional deve levar em conta o bem-estar social em sentido mais amplo.

Santos (1999) também faz referência ao papel que a Contabilidade deve desempenhar no contexto social, explicando que essa disciplina é chamada a colaborar na construção de relações mais saudáveis entre empresa e sociedade. Esse autor considera que, para tanto, um dos possíveis instrumentos de evidenciação pode ser o chamado Balanço Social.

Referindo-se à nova relação da Contabilidade com a sociedade, Santos acrescenta as seguintes considerações:

"Hoje em dia, não se pode mais admitir que a Contabilidade esteja sendo preparada para uso exclusivo dos mesmos usuários de 4 ou 5 décadas atrás. A Contabilidade passou a ter relevância no cenário econômico como um todo, deixando de ser instrumento importante apenas no auxílio prestado no cálculo e identificação dos valores que servem como base para recolhimento de impostos, análise para concessão de crédito ou pagamento de dividendos, e com isso começa a ocupar espaço bastante importante nas relações sociais". (1999:8)

Quanto ao Balanço Social, entre as principais informações que podem ser apresentadas nesse relatório contábil, destacam-se: nível de emprego, relações profissionais, formação profissional, condições de higiene e segurança, medidas de proteção ao meio ambiente, distribuição da riqueza gerada pela empresa etc. Não se trata de uma simples peça de marketing empresarial, mas de um autêntico instrumento de apoio à cidadania na medida em que contribui para a democratização das informações contábeis. Com esse relatório, tanto um investidor sofisticado quanto o mais singelo empregado podem encontrar na Contabilidade meios de exercitar sua cidadania.

Segundo De Luca (1998:26), um dos aspectos de maior relevância que deve ser evidenciado no Balanço Social diz respeito a projetos da empresa relacionados à preservação do meio ambiente. A título de exemplo, essa autora destaca que a avaliação do passivo ambiental pode exercer impactos significativos no valor econômico da empresa. Isso deriva da consciência de que não se pode admitir progresso econômico à custa da degradação ambiental. Assim, não é difícil prever que empresas que apresentem risco potencial ao meio ambiente deverão enfrentar grandes dificuldades de sobrevivência em futuro próximo.

A DVA - Demonstração do Valor Adicionado é outro relatório por meio do qual a Contabilidade pode oferecer relevante contribuição à ordem social. Seu principal objetivo é demonstrar como se deu a distribuição da riqueza geral pela entidade entre os diversos agentes que concorrem para a sua obtenção: acionistas, empregados, governo e financiadores.

Segundo De Luca (1998:32), a DVA está intimamente associada ao conceito de responsabilidade social e surgiu para atender às necessidades de informações dos usuários sobre o valor da riqueza criada pela empresa e sua utilização. Essa autora explica que "o valor adicionado de uma empresa representa o quanto de valor ela agrega aos insumos que adquire num determinado período e é obtido, de forma geral, pela diferença entre as vendas ou produção e o total dos insumos adquiridos de terceiros".

Discorrendo sobre as vantagens da DVA como instrumento de equilíbrio das relações sociais, Santos (1999) salienta que essa demonstração contábil pode servir, inclusive, para auxiliar no cálculo do PIB e definir outros indicadores sociais de grande importância. Identificação da carga tributária por setores da economia, informações sobre remuneração de pessoal por segmento econômico ou por regiões e políticas de remuneração de capital de terceiros são alguns exemplos de dados relevantes que podem ser extraídos da referida demonstração.

\subsection{A Contabilidade no contexto da Lei de Responsabilidade Fiscal}

No que se refere às organizações públicas, observa-se que o ordenamento jurídico do país também 
põe em destaque o papel da Contabilidade como instrumento de apoio à construção da ordem social. Um dos exemplos mais recentes pode ser encontrado na Lei de Responsabilidade Fiscal. Ao tratar da transparência da gestão fiscal, essa lei estabelece que se dê ampla divulgação a instrumentos de evidenciação, tais como planos, orçamentos, leis de diretrizes orçamentárias, pareceres de prestações de contas, relatórios de gestão fiscal etc.

Quanto aos sistemas de informações contábeis, destaca-se a necessidade de a Administração Pública manter sistema de custos que permita a avaliação e o acompanhamento da gestão orçamentária, financeira e patrimonial. De igual modo, salienta-se a necessidade de divulgar com clareza todos os eventos de interesse contábil, principalmente os relacionados a compromissos assumidos junto a terceiros.

Como se observa, a Lei de Responsabilidade Fiscal contribui para consagrar o relacionamento entre o governo, o público e a informação contábil. Isso se torna mais evidente, quando se considera que a mesma determina, em seu artigo de no 49, que as contas apresentadas pelo chefe do Poder Executivo deverão ficar disponíveis, durante todo o exercício, no respectivo Poder Legislativo e no órgão técnico responsável por sua elaboração, para consulta e apreciação pelos cidadãos e instituições da sociedade. Com isso, a sociedade é guindada à condição de usuário privilegiado das informações contábeis, e estas, por sua vez, assumem claramente o status de instrumento de cidadania.

\section{Conclusões}

Sob a abordagem sociológica, a teoria contábil considera que o papel da Contabilidade não se limita ao fornecimento de informações necessárias à otimização de decisões de caráter econômico. Além disso, deve contemplar os interesses da sociedade de forma mais ampla. Isso nos autoriza a afirmar que, sob o aspecto sociológico, a ordem social passa a ser o critério básico de avaliação dos procedimentos contábeis adotados em determinado ambiente.
Um dos meios que a Contabilidade pode utilizar para ajudar a promover a ordem social é o chamado Balanço Social, haja vista que nesse tipo de relatório a empresa abre-se ao diálogo com os diversos agentes que, direta ou indiretamente, contribuem para o sucesso dos negócios. De modo específico, o referido Balanço pode: contribuir para estimular posturas éticas e transparentes no âmbito corporativo, divulgar a contribuição que a empresa presta ao desenvolvimento de pesquisas e tecnologias, subsidiar negociações com empregados, contribuir para democratizar as relações com o público interno e externo, fortalecer as bases de confiança e transparência entre a empresa e os stakeholders, permitir acompanhar a evolução do processo de responsabilidade social da empresa etc.

A contribuição que a Semiótica e a Teoria da Comunicação podem oferecer para potencializar o papel da Contabilidade como instrumento de construção da ordem social pode se manifestar em diversos aspectos. Um dos principais diz respeito a uma das características qualitativas vitais à informação, que é a compreensibilidade. A variedade de públicos que poderão fazer uso do Balanço Social, por exemplo, exige que o mesmo seja elaborado com alto grau de compreensibilidade para facilitar o entendimento das informações que se pretende veicular. Nesse sentido, recomenda-se evitar o uso de termos excessivamente técnicos e considerar a necessidade de recorrer a outros recursos de evidenciação, tais como gráficos, tabelas etc. Além disso, a Teoria da Comunicação fornece metodologia útil para avaliar a eficácia do ato comunicativo, uma vez que nos permite identificar os fatores que influenciam a fidelidade da comunicação. Ela nos permite entender como se desenvolve o processo de comunicação e facilita a identificação dos elementos críticos para o êxito do ato comunicativo.

No que se refere à Semiótica, sua principal contribuição se expressa nas teorias que evidenciam o processo de construção dos significados. Uma delas é a Teoria dos Signos, segundo a qual os significados não são propriedades das palavras, mas faculdades mentais dependentes do contexto 
e de outros referenciais cognitivos. Outra importante contribuição da Semiótica é fornecida pela chamada Teoria da Percepção. Com esta, pode-se entender, por exemplo, que as informações contábeis só poderão ser aproveitadas pelos diversos estratos de usuários, quando eles percebem sua relevância. Isso exige, por parte da empresa, amplo conhecimento das expectativas e necessidades dos diversos agentes que com ela se relacionam.

Dada a influência que a contabilidade pode exercer em relação ao desenvolvimento e manu- tenção da ordem social, recomenda-se que os órgãos de classe e instituições responsáveis pelo desenvolvimento e divulgação do saber contábil continuem estimulando a publicação de relatórios que contemplem informações de natureza social. Além disso, recomenda-se que estudos sejam realizados no sentido de verificar até que ponto as demonstrações contábeis fornecem informações dessa natureza e se as mesmas se apresentam compreensíveis aos diversos públicos a que se destinam.

\section{REFERÊNCIAS BIBLIOGRÁFICAS}

ANTHONY, Robert Newton et al. Accounting: text and cases. Chicago: Irwin,1975.

BEDFORD, Norton M.; BALADOUNI, Vahe. A communication theory approach to accounting. Accounting review, Oct. 1962. BELADOUNI, Vahe. The Accounting Perspective Re-Examined. Accounting review, v. 41, n. 2, p. 215-225, Apr. 1966.

BELKAOUI, Ahmed Riahi. Accounting theory. 4. ed. London: Business Press; Thomson Learning, 2000.

BIERMAN Jr., Harold; DREBIN, Alan R. Contabilidade gerencial. Tradução de Mauro Batista Temer. 2.ed. Rio de Janeiro: Guanabara Dois, 1979.

BIO, Sérgio Rodrigues. Sistemas de informação. São Paulo: Atlas, 1985.

CHAMBERS, Raymond J. Accounting, evaluation and economic behavior. Englewood Cliffs, New Jersey: Prentice-Hall, 1966.

COELHO NETTO, J. Teixeira. Semiótica, informação e comunicação. 4. ed. São Paulo: Perspectiva, 1996.

DE LUCA, Márcia Martins Mendes. Demonstração do valor adicionado. São Paulo: Atlas, 1998.

DIAS FILHO, José Maria. Características qualitativas da informação contábil: o problema da compreensibilidade à luz da teoria semiótica e da comunicação. 2001. Dissertação (Mestrado) Faculdade de Economia e Administração da Universidade de São Paulo, São Paulo, 2001.

ECO, Umberto. Tratado geral de semiótica. 3. ed. São Paulo: Perspectiva, 2000.

ETHERIDGE, Harian Lynn. An examination of Semiotic Theories of accounting accruals. 1991. Tese (Ph. D.), Louisiana State University, Lousiana, 1991.

FINANCIAL ACCOUNTING STANDARDS BOARD-FASB. Statement of financial accounting concepts. Qualitative characteristics of accounting information, n. 2, May 1980.

HENDRIKSEN, Eldon S.; BREDA, Michael F. Van. Teoria da contabilidade. Tradução de Antônio Zoratto Sanvicente. 5. ed. São Paulo: Atlas, 1999.

HORNGREN, Charles T. Accounting for management control. Englewood Cliffs, NJ: Prentice-Hall, 1974.

IJIRI, Y. Theory of accounting measurement. Sarasota, FL: American Accounting Association, 1975.

IUDÍ́CIBUS, Sérgio de. Teoria da contabilidade. 5. ed. São Paulo: Atlas, 1997.

KAM, Vernon. Accounting theory. New York: John Wiley \& Sons, 1986.

KAPLAN, Robert S. et al. Management Accounting. 2. ed. New Jersey: Prentice-Hall, 1995.

LAURETTI, Lélio. Relatório Anual: o que uma sociedade por ações deve informar aos investidores. São Paulo: Saraiva, 1998.

LITTLETON, A. C.; ZIMMERMAN, V. K. Accounting theory: continuity and change. New Jersey: Prentice-Hall, 1962.

MARTINS, Gilberto de Andrade. Manual para elaboração de monografias e dissertações. 2. ed. São Paulo: Atlas, 1994.

MASON, Richard O.; SWANSON, E. Burton. Measurement for management decision. Addison-Wesley series on decision support. Massachusetts: Addison-Wesley Publishing, 1981.

MATTESSICH, Richard. Critique of accounting: examination of the fundations and normative structure of an applied discipline. London: Quorum Books, 1995.

MERLEAU-PONTY, Maurice. Fenomenologia da percepção. Tradução Carlos Alberto Ribeiro de Moura. 2. ed. São Paulo: Martins Fontes, 1999.

MOONITZ, Maurice. The basic postulates of accounting. New York: AICPA, 1961.

MORRIS, Charles W. Fundamentos da teoria dos signos. Tradução Paulo Alcoforado e Milton José Pinto. São Paulo: Edusp, 1976. MOST, Kenneth S. Accounting theory. 2. ed. Columbus, Ohio: Grid Publishing, Inc., 1982.

NAKAGAWA, Masayuki; PRETTO, Clea B. Macagnan. An interdisciplinary view of accountancy in Brazil, In: ASIAN. 
PACIFIC CONFERENCE ON INTERNATIONAL ACCOUNTING ISSUES, 12., 2000. Anais... China, 2000.

NEIVA Jr., Eduardo. Comunicação: teoria e prática social. São Paulo: Brasiliense, 1991.

NÖTH, Winfried. Handbook of Semiotics. Bloomington, USA: Indiana University Press, 1995.

PEIRCE, Charles S. Semiótica. Tradução José Teixeira Coelho Netto. 3. ed. São Paulo: Perspectiva, 1999.

RIAHI-BELKAOUI, Ahmed. The linguistic shaping of accounting. London: Quorum Books, 1995.

SANTAELLA, Lucia. A percepção: uma teoria semiótica. 2. ed. São Paulo: Experimento, 1998.

. A teoria geral dos signos. São Paulo: Pioneira, 2000.

SANTOS, Ariovaldo dos. Demonstração contábil do valor adicionado - DVA: um instrumento para medição da geração e distribuição de riqueza das empresas. 1999. Tese (Livre-Docência) Faculdade de Economia e Administração da Universidade de São Paulo, São Paulo, 1999.

SCHRICKEL, Wolfgang Hurt. Demonstrações financeiras. 2. ed. São Paulo: Atlas, 1999.

SELLTIZ, Claire et al. Research methods in social relations. New York: Holt, Rinehart and Winston, 1966.

SHANNON, Claude E.; WEAVER, Warren. The mathematical theory of communication. Urbana, Illinois: University of Illinois Press, 1949.

THEÓFILO, Carlos Renato. Uma abordagem epistemológica da pesquisa em contabilidade. 2000. Dissertação (Mestrado) Faculdade de Economia e Administração da Universidade de São Paulo, São Paulo, 2000. 